\title{
Short communication: Snapshot of industry milk hauling practices in the western United States
}

\author{
Eva Kuhn, Lisbeth Meunier-Goddik, and Joy G. Waite-Cusic ${ }^{1}$ \\ Department of Food Science and Technology, Oregon State University, Corvallis 97331
}

\begin{abstract}
The Pasteurized Milk Ordinance (PMO) mandates milk hauling sanitation and operational practices; however, the use of vague language (i.e., "as needed") and gaps in processes lead to variability in industry practices. Our aim was to characterize industry milk hauling practices and identify areas that may be an unexplained source of contamination in the dairy processing continuum, and communicate this information with industry to cultivate best practices. The objectives of this study were to (1) survey industry hauling sanitation and operation practices in the Pacific Northwest region of the United States, and (2) quantify microbial populations [aerobic plate count (APC), lactic acid bacteria, coliforms] on the internal surfaces of transfer hoses (tanker and receiving bay) to determine their potential contribution to the microbiological quality of raw milk. Eleven facilities ( $78 \%$ response rate) participated in our survey. All facilities surveyed were compliant with the $\mathrm{PMO}$; however, overall milk reception layout, sanitation practices, and routine maintenance greatly varied between facilities. Farm hose samples $(\mathrm{n}=115)$ had significantly higher microbial loads (APC: mean $4.7 \log \mathrm{cfu} / 100 \mathrm{~cm}^{2}$; median $5.1 \mathrm{log}$ $\left.\mathrm{cfu} / \mathrm{cm}^{2}\right)$ than receiving hose samples $(\mathrm{n}=57$; APC: mean: $2.1 \log \mathrm{cfu} / 100 \mathrm{~cm}^{2}$; median $1.9 \log \mathrm{cfu} / 100$ $\mathrm{cm}^{2}$ ). Microbial populations on transfer hose surfaces did not correlate with time since last cleaning for either tanker or receiving bay hoses. Microbial content of farm hoses is likely to reflect the microbial quality of the previous milk transferred through the hose, making onfarm management practices the primary consideration to maintain low microbiological counts downstream. Upon arrival at the processor, $10 \%$ of farm hoses were missing caps. Although this did not correlate with elevated microbiological counts, uncapped farm hoses are exposed to the farm environment, provide opportunity for contamination, and are in violation of the PMO.
\end{abstract}

Received June 2, 2017.

Accepted November 3, 2017.

${ }^{1}$ Corresponding author: joy.waite-cusic@oregonstate.edu
Through observations made during our studies, manual cleaning procedures appear to be a major weakness in hauling practices and need more attention. Recognizing and communicating variability and areas of weakness allows industry to elevate their hauling sanitation and operational practices to maintain optimum milk microbiological quality.

Key words: milk hauling, milk transportation, raw milk microbiological quality, transfer hoses

\section{Short Communication}

Optimum milk microbiological quality is established as soon at the milk is collected from the teat of the cow (Doyle et al., 2017). As milk is further manipulated by handling, transportation, and processing, microbiological quality can only be negatively influenced due to opportunistic microbial contamination (Marchand et al., 2012). For this reason, it is critical that best sanitation and operation practices are implemented at every step of the process to produce the highest quality dairy products. The dairy industry has expressed concerns that hauling sporadically contributes to reduced milk quality. Milk hauling includes the entire process from when raw milk is transferred from the farm bulk tank to tanker, transported, and transferred from tanker into silo storage at a processing facility. Repeated tanker usage (without cleaning between loads) reduces costs in energy, water and chemical usage, and sanitation labor (USDA, 2014). The grade A Pasteurized Milk Ordinance (PMO) defines and mandates standard hauling operation and sanitation practices, such as repeated use of tankers for up to $24 \mathrm{~h}$ before a mandatory cleanin-place (CIP; Food and Drug Administration, 2015). Previous research has verified that when standard practices are followed, hauling is unlikely to compromise bulk raw milk quality (Darchuk et al., 2015a,b).

Although the PMO clearly defines a necessary sanitation schedule for tankers, maintenance and sanitation of other accessory components are vaguely defined in the PMO with a recommended schedule of "as needed" (Food and Drug Administration, 2015). Knowledge gaps exist in understanding how hauling practices can nega- 
tively affect the dairy processing continuum, but it is speculated that a negative effect typically occurs when a collection of practices is not implemented as intended (Teh et al., 2011, 2012; Darchuk et al., 2015a,b). For example, lacking a dynamic CIP system validation and verification program increases the risk of inadequate sanitation. Tanker components and accessories such as gaskets, pumps, and caps that require manual cleaning (clean-out-of-place) are another area of concern due to variability in cleaning schedules as well as cleaning efficacy due to personnel (Memisi et al., 2015).

The overarching hypothesis of our research is that milk hauling sanitation and operation practices have the potential to negatively contribute to the microbiological quality of raw milk and potentially affect finished product quality through thermo-resistant microbial enzyme activities. However, if this occurs, it is likely infrequent and difficult to measure due to the scale of production. To identify potential contributing factors, it is essential to accurately characterize various aspects of hauling practices. We hypothesized that various milk transportation accessories (hoses, pumps, and associated parts) contribute negatively to raw milk quality. The objectives of this study were (1) to characterize sanitation and operation practices associated with collection of milk on farm and delivery of milk at processing facilities in the Pacific Northwest, and (2) to quantify the microbial load of accessory hauling components (i.e., transfer hoses) in a commercial setting to evaluate the potential effect on raw milk quality.

All licensed fluid milk processors in Oregon and Washington $(\mathrm{n}=12)$ along with the 2 largest cheese producers in Oregon were targeted for participation in the survey. Quality assurance and milk receiving personnel of various positions (operators, supervisors, managers) were contacted via email to request their participation in an industry survey about milk hauling and receiving practices in their facilities. Following initial contact, industry representatives were provided with an electronic copy of the survey via follow-up email and requested to return the survey via postal mail, email, or retrieval during an on-site visit to the facility. The survey consisted of 12 questions to characterize type and frequency of sanitation and operating procedures related to milk hauling and receiving practices. Observations and responses were compiled and evaluated to determine commonalities and gaps in practices with reference to the PMO regulations.

During 2 consecutive days of operation in March 2017, transfer hoses were sampled at a single large milk processing facility. Interior surfaces $\left(100 \mathrm{~cm}^{2}\right)$ of receiving bay hoses and tanker farm hoses were sampled using $3 \mathrm{M}$ sponge swabs with buffered peptone water (3M, Maplewood, MN). Farm hoses located on tanker trucks
( $\mathrm{n}=115)$ were sampled upon arrival at the receiving bay with the license plate and time of last CIP documented to evaluate time since CIP as a contributing factor. Farm hose swab samples were obtained by inserting the swab approximately $20 \mathrm{~cm}$ into the hose and sampling an area of $100 \mathrm{~cm}^{2}$. Receiving bay hoses $(\mathrm{n}=$ 4) were sampled once every hour over the course of 6 h (6 samples/hose per day). Receiving bay hose swab samples were obtained from the first $60 \mathrm{~cm}$ of length for a given hose. To ensure that any given $100 \mathrm{~cm}^{2}$ surface of the receiving bay hoses was not sampled more than once during each sampling day, the distance from the end of the hose to the sample site for each collection point was randomized at the beginning of the trial.

Samples were immediately cooled $\left(<4.4^{\circ} \mathrm{C}\right)$, transported to the laboratory, and processed within $24 \mathrm{~h}$ of collection. Samples were serially diluted in $0.1 \%$ peptone water and plated on aerobic plate count (APC) Petrifilm (3M), coliform Petrifilm (3M), and de Man, Rogosa, and Sharpe Agar (Difco, Sparks, MD). Petrifilms were incubated at $30^{\circ} \mathrm{C}$ for 24 to $48 \mathrm{~h}$, and de Man, Rogosa, and Sharpe plates were incubated for $30^{\circ} \mathrm{C}$ for $72 \mathrm{~h}$ under anaerobic conditions. Counts were reported as $\log \mathrm{cfu} / \mathrm{cm}^{2}$.

Survey results were compiled and tabulated. Transfer hose microbiological counts were analyzed by one-way ANOVA in JMP Pro 13 (SAS Institute Inc., Cary, NC).

Our survey highlighted milk reception layout, operational and sanitation practices, and routine maintenance practices (Table 1). Eleven of the 14 facilities (78\%) completed and returned the milk hauling survey. Regulatory practices are outlined in PMO section 7 (12p.) Cleaning and Sanitizing of Containers and Equipment and Appendix B. Milk Sampling, Hauling and Transportation (Food and Drug Administration, 2015).

A majority $(55 \%)$ of receiving bays in the Pacific Northwest are partially enclosed (facilities with an overhead cover, but lacking complete sides/wall). The remainder of receiving facilities $(45 \%)$ are fully enclosed. Facilities ranged in the number of receiving bays ranges from 1 to 3 , where the majority of facilities have 2 receiving bays (64\%), indicating that they can unload multiple tankers at a time and/or continue receiving if one bay is unavailable due to sanitation schedule or maintenance. The number of receiving hoses per bay range from 1 to 5 with 2 hoses being the most common response (45\%). Most facilities have more receiving hoses than bays. This allows for flexibility during operation to support cleaning activities and divert milk to alternative storage sites (surplus milk). All facilities reported that their receiving hoses are hung during storage and between receiving loads. These practices are in compliance with the PMO mandate that receiv- 
Table 1. Milk hauling and receiving practices used by commercial dairy facilities in the northwest region of the United States

\begin{tabular}{|c|c|}
\hline Survey topic & $\begin{array}{l}\text { No. of facilities } \\
\qquad(\mathrm{n}=11)^{1}\end{array}$ \\
\hline \multicolumn{2}{|l|}{ Overview of milk receiving operation } \\
\hline \multicolumn{2}{|l|}{ Receiving bay layout } \\
\hline Full enclosure & $5(45)$ \\
\hline Partial enclosure, overhead cover & $6(55)$ \\
\hline \multicolumn{2}{|l|}{ No. of receiving bays } \\
\hline 1 & $2(18)$ \\
\hline 2 & $7(64)$ \\
\hline 3 & $2(18)$ \\
\hline \multicolumn{2}{|l|}{ No. of receiving hoses } \\
\hline 1 & $2(18)$ \\
\hline 2 & $5(45)$ \\
\hline 3 & $1(9)$ \\
\hline 4 & $2(18)$ \\
\hline 5 & $1(9)$ \\
\hline \multicolumn{2}{|l|}{ Receiving hose storage } \\
\hline Stored on ground & $0(0)$ \\
\hline Stored hanging & $11(100)$ \\
\hline \multicolumn{2}{|l|}{ Receiving hose style } \\
\hline Clamp + cap + gasket & $4(37)$ \\
\hline Threaded cap & $5(45)$ \\
\hline Other & $2(18)$ \\
\hline \multicolumn{2}{|l|}{ No. of daily tanker receipts } \\
\hline $0-5$ & $2(18)$ \\
\hline $6-10$ & $5(45)$ \\
\hline $11-30$ & $4(37)$ \\
\hline \multicolumn{2}{|l|}{ Milk receiving sample collection } \\
\hline Aseptic & $1(9)$ \\
\hline Dipper & $10(91)$ \\
\hline \multicolumn{2}{|c|}{ Frequency of replacing cleaning equipment such as buckets and brushes } \\
\hline Routine; $2-4$ wk & $1(9)$ \\
\hline As needed & $10(91)$ \\
\hline \multicolumn{2}{|c|}{ Frequency of replacing gaskets, farm hoses, and other parts susceptible to deterioration } \\
\hline Routine; 3-6 mo & $2(18)$ \\
\hline As needed & $9(82)$ \\
\hline \multicolumn{2}{|c|}{ Frequency of small part cleaning/sanitizing } \\
\hline Hourly/between tankers & $2(18)$ \\
\hline Daily only & $2(18)$ \\
\hline At least once a day; as needed & $7(64)$ \\
\hline \multicolumn{2}{|l|}{ Cleaning and sanitation practices } \\
\hline \multicolumn{2}{|l|}{ Tanker CIP schedule } \\
\hline After each load & $4(37)$ \\
\hline Once per $24 \mathrm{~h}$ & $7(63)$ \\
\hline \multicolumn{2}{|l|}{ Routine maintenance } \\
\hline \multicolumn{2}{|l|}{ Validate CIP system ${ }^{2}$} \\
\hline Daily & $1(9)$ \\
\hline Monthly & $1(9)$ \\
\hline Quarterly & $3(27)$ \\
\hline Annually & $6(55)$ \\
\hline
\end{tabular}

ing hoses be capped and hung up when not in use (Food and Drug Administration, 2015). The most common cap styles used in the region were threaded cap (45\%) and tri-clamp with cap (37\%); however, 2 facilities reported an alternative style (i.e., mounted cap housing).

The frequency of milk delivery to processing facilities in the Pacific Northwest varied substantially through- out the industry. Most these facilities $(82 \%)$ receive $>6$ tanker loads of raw milk per day. The largest number of tankers received was 30 per day. The smallest processing facility received 2 to 3 tankers every other day. Prior to unloading, raw milk from each tanker load must be tested for the presence of antibiotics ( $\beta$-lactams) and milk temperature must be checked to verify it is below 
the cutoff $\left(<7.2^{\circ} \mathrm{C}\right.$; Food and Drug Administration, 2015). The majority of facilities collect milk receiving samples from the top hatch of the tanker using a sanitized stainless-steel dipper (91\%). One facility aseptically collects samples via an in-line where a syringe is punctured into a rubber-septum-covered sample port.

The PMO mandates that small parts such as hoses, caps, gaskets, and cleaning tools are replaced as needed. Cleaning and sanitation of small parts is completed a minimum of every $24 \mathrm{~h}$ and additionally as needed throughout daily use (Food and Drug Administration, 2015). Most facilities (82\%) replace gaskets and farm hoses as needed; however, $18 \%$ schedule routine replacement every 3 to 6 mo. Similarly, almost all facilities $(91 \%)$ replace cleaning equipment such as buckets and brushes as needed. A single facility reported having a routine replacement schedule for their cleaning tools of 2 to 4 wk. In the Pacific Northwest, most facilities clean and sanitize small parts (e.g., hoses, caps, gaskets) multiple times per day (82\%); however, some facilities $(18 \%)$ clean these parts once per day.

Tankers are permitted for continuous use within a 24-h period before required CIP treatment (Food and Drug Administration, 2015). Processors have the ability to mandate a more frequent sanitation schedule if desired. The majority of facilities (63\%) follow the PMO requirements allowing for repeated tanker use between CIP. Four facilities in this study implement a CIP treatment after each load of milk. Facilities that clean after every load tended to be ones that receive less than 10 loads per day.

The PMO requires validation of the CIP system at least annually (Food and Drug Administration, 2015). CIP system parameters that are checked in the validation process are (1) temperature, (2) flow and mechanical action, (3) conductivity, (4) time, and (5) equipment inspection (Memisi et al., 2015). Overall tanker sanitation is only as good as the efficacy of any given facility's regular practices (Darchuk et al., 2015a). To ensure adequate tanker sanitation, an effective validation and verification program needs to be established. Validating CIP systems more frequently could mitigate risks of inadequate sanitation. In our survey, $55 \%$ of facilities validate their CIP system on an annual basis. Several facilities indicated that CIP validation is performed more frequently: quarterly (27\%), monthly (18\%), and daily $(9 \%)$. It should be noted that daily validation is unlikely and is rather a daily verification activity, such as ATP, microbiological, and residual protein swabs, and rinse samples. Luning et al. (2009) reported that industry personnel often confuse the concepts of validation and verification. It is essential that industry is comprehensive in sanitation validation and verification activities to ensure adequate tanker sanitation.
Transfer hoses are the connecting components used to transfer raw milk from producer on-farm bulk tank to processor storage silos. Farm hoses are used to transfer milk from farm bulk tanks into the tanker. They are constructed of transparent flexible plastic that meets the "3-A Sanitary Standards for Multiple-Use Plastic Materials Used as Product Contact Surfaces for Dairy Equipment, 20\#\#," and are typically 6.4 to 7.6 $\mathrm{cm}$ (2.5 to $3 \mathrm{in}$ ) in diameter and may be up to $46 \mathrm{~m}$ (150 ft) long (Food and Drug Administration, 2015). These hoses are accessed through the pump box and are stored either coiled or housed within a slanted pipe along the side of the tanker. Receiving hoses are used to unload milk from tankers and are constructed out of thick rubber material. The inside surfaces of these hoses are cleaned and sanitized as part of the tanker CIP at the frequency determined by the processor (after every load to once per $24 \mathrm{~h}$ ). While the tanker body is well insulated to maintain the bulk fluid temperature, these hoses and the residual milk within them quickly reach ambient temperature in between loads.

Figure 1 displays microbiological counts of tanker farm hoses $(\mathrm{n}=115)$. Mean APC was $4.7 \mathrm{log} \mathrm{cfu} / 100$ $\mathrm{cm}^{2}$ and ranged from 0.0 to $7.0 \mathrm{log} \mathrm{cfu} / 100 \mathrm{~cm}^{2}$. Mean lactic acid bacteria (LAB) count was $3.5 \log \mathrm{cfu} / 100$ $\mathrm{cm}^{2}$ and ranged from 0.0 to $5.4 \log \mathrm{cfu} / 100 \mathrm{~cm}^{2}$. Mean coliform count was $2.2 \log \mathrm{cfu} / 100 \mathrm{~cm}^{2}$ and ranged from 0.0 to $6.3 \mathrm{log} \mathrm{cfu} / 100 \mathrm{~cm}^{2}$. Time (h) since last CIP was categorized into 5-h increments; microbiological counts did not increase with time since last CIP (one-

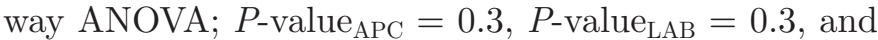
$P$-value coliforms $=0.8)$. The vast majority of tankers $(93 \% ; 107 / 115)$ were under $24 \mathrm{~h}$ since last CIP. Of the 8 tankers $(7.0 \%)$ that were past $24 \mathrm{~h}$ since last cleaning, $3(2.7 \%)$ of these tankers collected the last load before $24 \mathrm{~h}$ since first use (permitted by the PMO). The remaining 5 loads $(4.3 \%)$ were past $24 \mathrm{~h}$ since first use: 3 loads were from unique tankers and may have been single-use, long-haul loads where $72 \mathrm{~h}$ use is permitted for grade B milk, and 2 loads were from the same tanker and collected $\sim 6 \mathrm{~h}$ apart (42 and $48 \mathrm{~h}$ since last cleaning). With the exception of the one tanker that was $>40 \mathrm{~h}$ overdue for cleaning, all tankers were in compliance with the PMO.

High variability in farm hose microbial counts was observed; however, there was no correlation with time since last CIP or number of loads hauled. For example, we sampled the farm hoses from the same tanker up to 3 times per day that did not increase in microbial load (data not shown). The internal surface of tanker farm hoses sampled in this study had higher levels of microbial contamination $(\mathrm{APC}$ mean $=4.7 \mathrm{log}$ $\mathrm{cfu} / 100 \mathrm{~cm}^{2}$ ) compared with raw milk contact surfaces reported in previous studies. Darchuk et al. (2015a) re- 
ported that internal surfaces of tankers averaged $3.4 \mathrm{log}$ cfu/900 $\mathrm{cm}^{2}$; however, Teh et al. (2012) demonstrated the potential for biofilm formation that could lead to contamination as high as $7.6 \log \mathrm{cfu} / \mathrm{cm}^{2}$. It should be noted that temperature conditions for this study were extreme $\left(25^{\circ} \mathrm{C}\right.$ for $\left.24 \mathrm{~h}\right)$, which would be unlikely in the United States (Darchuk et al., 2015b). Although the bacterial counts reported in the current study demonstrate that transfer hoses can harbor elevated levels of bacteria, these counts align with PMO mandates for standard plate count $(<5.5 \log \mathrm{cfu} / \mathrm{mL}$ of bacteria) for commingled grade A raw milk (Food and Drug Administration, 2015).
According to the PMO (section 7, item 15p.A), "hoses must be capped or otherwise properly protected when not in use, and should only be exposed to external elements for the brief moment of uncapping and connecting to a pump" (Food and Drug Administration, 2015). During sample collection of tanker farm hoses, we observed 16 hoses (14\%) that were missing caps. Statistical analysis showed a significant difference $(P<0.0001)$ in microbial contamination depending on the presence or absence of a hose cap on the tanker farm hose. Tanker farm hoses without caps (Figure 1: open markers) had significantly lower levels of microbial contamination (APC, LAB, and coliforms) than

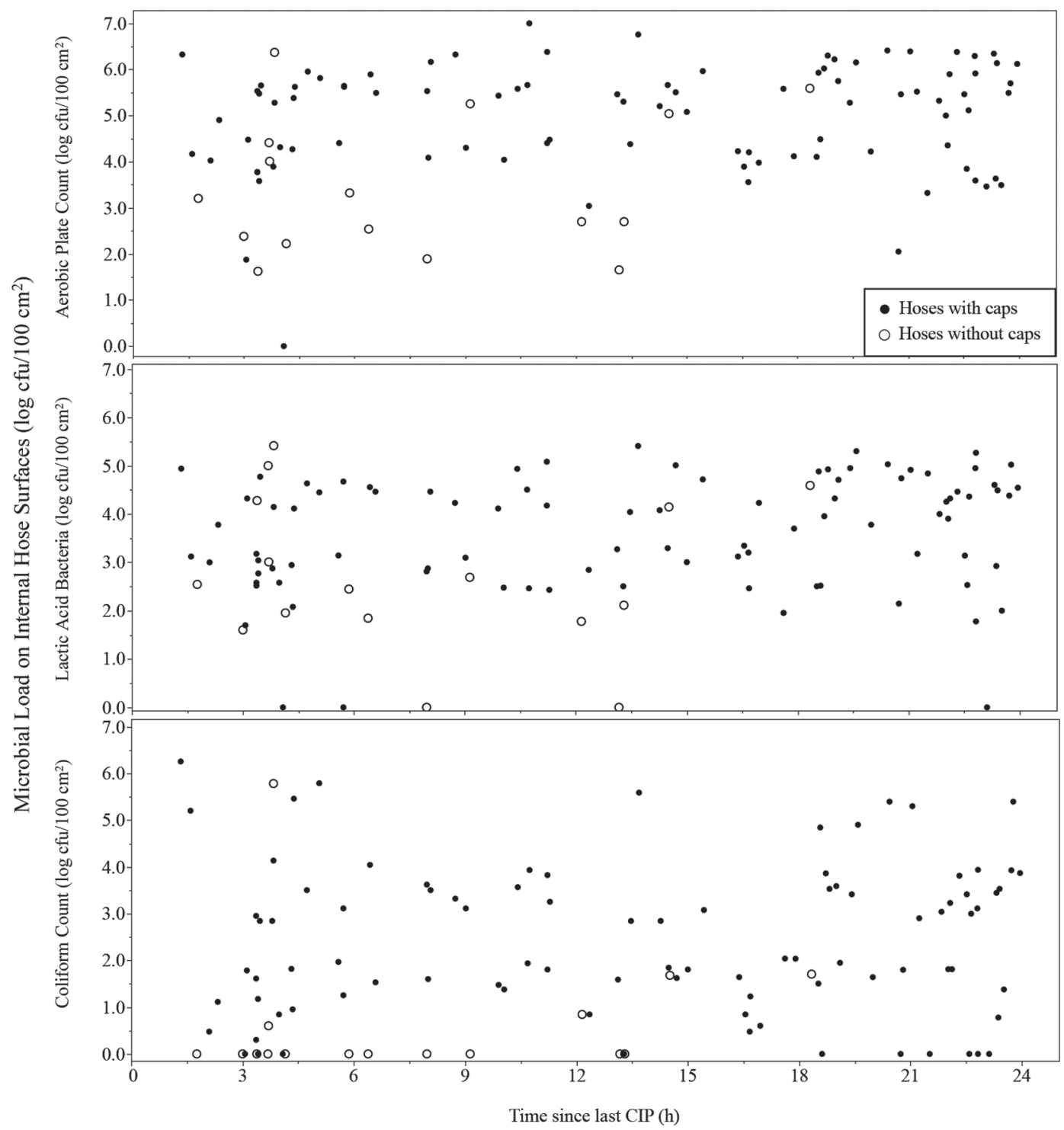

Figure 1. Scatter plot of microbial concentrations $\left(\log \mathrm{cfu} / 100 \mathrm{~cm}^{2}\right)$ of aerobic plate count on the internal surfaces of tanker farm hoses as a function of time $(\mathrm{h})$ since last clean-in-place $(\mathrm{CIP})$ of tanker $(\mathrm{n}=115$ hoses $)$ at a large commercial facility. Closed markers indicate tanker farm hoses with caps $(\mathrm{n}=91)$, and open markers indicate tanker farm hoses without caps $(\mathrm{n}=16)$. Samples collected with time since last CIP of $>24 \mathrm{~h}$ were excluded from this figure. Limit of detection $=1 \mathrm{cfu} / 100 \mathrm{~cm}^{2}$. 
those with caps (Figure 1: closed markers). This finding was unexpected. Tanker farm hoses are dragged on the ground when being unloaded from the tanker to connect to the farm bulk tank. When the cap is missing, there is an increased likelihood of soil and farm environmental contaminants to enter the open hose; however, it is also possible that the lack of cap may contribute to improved draining and reduced adherence of bacterial cells to the surface of the hose during reloading of the hose on the truck. It is important to note that not all hoses without caps had low levels of microbial contamination; therefore, additional research would be necessary to identify specific practices by the tanker operators that lead to reduced contamination. Several tanker farm hose caps had visible fouling, suggesting that regular cleaning and sanitation of these caps may be overlooked by several tanker operators.

Receiving hoses had average APC, LAB, and coliform counts of 2.1, 0.8, and $0.6 \log \mathrm{cfu} / 100 \mathrm{~cm}^{2}$ ( $\mathrm{n}=$ 56) during standard use during consecutive sampling days in March 2017. Mean temperature on the days of collection was $22^{\circ} \mathrm{C}$. No trends were observed in microbial growth with hourly sampling, and there was a lack of variability between individual receiving bay hoses (1-way ANOVA; $P>0.05$ ). Low counts in receiving hoses were expected due to high volume intake $(\sim 280$ tankers per day), where receiving hoses are almost always in constant use, which mitigates the opportunity for microbial growth on internal surfaces. Repeated use of receiving hoses does not appear to be a source of contamination in milk hauling.

One challenge to consider with industry studies is the observation effect (e.g., Hawthorne effect), where there is the possibility of personnel performing at a higher level when being observed in comparison to unobserved "normal" operation (McCambridge et al., 2014). Despite this challenge, we did observe several weaknesses in hauling sanitation and operations practices:

1. One area of hauling that needs more attention is manual cleaning procedures. We observed personnel neglecting to disassemble and use detergent to clean pump boxes, dome lids and air vents, and gaskets. In fact, one tanker had so much fouling on the air vent that the cap could barely be removed. While sampling, we witnessed several dirty pump boxes and hose caps with visible fouling on the internal surface. In contrast to CIP systems, manual cleaning requires more human involvement. During tanker sanitation, the farm pump needs to be disassembled and manually cleaned with detergent; however, the tanker and farm hose can be connected to the CIP system without ever dissembling the pump.
2. Most facilities do not have an established routine for replacing small parts (e.g., gaskets, buckets, brushes) that are susceptible to deterioration. Deteriorated gaskets were observed on one of the receiving hoses (age was unknown). The cleanability of deteriorated gaskets is reduced, providing an optimal environment to support biofilm formation (Storgards et al., 1999). Longevity of parts susceptible to deterioration depends on material and usage, but replacement is recommended as a preventative measure rather than replacement when functionality is lost. Gasket longevity can be extended by not overtightening clamps.

Variability exists in industry milk hauling sanitation and operation practices. Negative effects from hauling appear to be sporadic and difficult to measure due to the scale of production; however, weaknesses in practices can compound and potentially compromise microbiological quality of raw milk and affect finished product quality. Characterizing variability of hauling practices aids in identifying and communicating best practices to elevate industry practices and contribute to better dairy product quality. In the modern dairy industry, repeated tanker and accessory usage is essential for economic reasons; it reduces chemical and water usage, time, and money. Therefore, hauling sanitation and operating procedures must be efficient and effective as part of the production of high-quality dairy products. Current hauling practices are sufficient when practices are implemented as intended; however, we have demonstrated that variability in industry hauling practices exist, even though the survey responses were in alignment with the PMO. The most effective way to mitigate poor practices is to educate and monitor personnel on proper use of cleaning and sanitizing agents and procedures (Kurt and Ozilgen, 2013). Additionally, when educating personnel, it is important to emphasize food safety and quality aspects to clarify why procedures need to be followed. It is also recommended that industry implement thorough preventative maintenance programs, including routine replacement of hauling accessories susceptible to deterioration, such as gaskets, farm hoses, and cleaning buckets and brushes.

\section{ACKNOWLEDGMENTS}

The authors thank the Dairy Research Institute (Rosemont, IL) for funding this research. We are grateful for the insight, collaboration, and support from our industry partners. An additional thank you to Danton Batty and Alexander Emch for their assistance in sample collection and to Javier Gasper-Hernandez and 
Ashley Hale (all from Oregon State University, Corvallis) for performing the microbiological testing.

\section{REFERENCES}

Darchuk, E., L. Meunier-Goddik, and J. Waite-Cusic. 2015a. Impact of commercial hauling practices and tanker cleaning treatments on raw milk microbiological quality. J. Dairy Sci. 98:7384-7393.

Darchuk, E., L. Meunier-Goddik, and J. Waite-Cusic. 2015b. Short communication: Microbial quality of raw milk following commercial long-distance hauling. J. Dairy Sci. 98:8572-8576.

Doyle, C. J., D. Gleeson, P. W. O'Toole, and P. D. Cotter. 2017. Impacts of seasonal housing and teat preparation on raw milk microbiota: A high-throughput sequencing study. Appl. Environ. Microbiol. 83:e02694-16.

Food and Drug Administration. 2015. Grade "A" Pasteurized Milk Ordinance. US Department of Health and Human Services Public Health Service, Washington, DC.

Kurt, L., and S. Ozilgen. 2013. Failure mode and effect analysis for dairy product manufacturing: Practical safety improvement action plan with cases from Turkey. Saf. Sci. 55:195-206.

Luning, P. A., W. J. Marcelis, J. Rovira, M. Van der Spiegel, M. Uyttendaele, and L. Jacxsens. 2009. Systematic assessment of core assurance activities in a company specific food safety management system. Trends Food Sci. Technol. 20:300-312.
Marchand, S., J. De Block, V. De Jonghe, A. Coorevitis, M. Heyndrickx, and L. Herman. 2012. Biofilm formation in milk production and processing environments; influence on milk quality and safety. Compr. Rev. Food Sci. Food Saf. 11:133-147.

McCambridge, J., J. Witton, and D. R. Elbourne. 2014. Systematic review of the Hawthorne effect: New concepts are needed to study research participation effects. J. Clin. Epidemiol. 67:267-277.

Memisi, N., V. S. Moracanin, M. Milijasevic, J. Babic, and D. Djukic. 2015. CIP cleaning processes in the dairy industry. Procedia Food Sci. 5:184-186.

Storgards, E., H. Simola, A. M. Sjoberg, and G. Wirtanen. 1999. Hygiene of gasket materials used in food processing equipment part 2: Aged material. Food Bioprod. Process. 77:146-155.

Teh, K. H., S. Flint, J. Palmer, P. Andrewes, P. Bremer, and D. Lindsay. 2012. Proteolysis produced within biofilms of bacterial isolates from raw milk tankers. Int. J. Food Microbiol. 157:28-34.

Teh, K. H., S. Flint, J. Palmer, D. Lindsay, P. Andrewes, and P. Bremer. 2011. Thermo-resistant enzyme-producing bacteria isolated from the internal surfaces of raw milk tankers. Int. Dairy J. 21:742-747.

United States Department of Agriculture-Economic Research Service (USDA-ERS). 2014. Food and Beverage Manufacturing. Accessed May 11, 2017. https://www.ers.usda.gov/topics/food-markets -prices/processing-marketing/manufacturing.aspx. 